\title{
LONGITUDINAL CHANGE OF REFRACTIVE ERROR IN INFANTS DURING THE FIRST YEAR OF LIFE
}

\author{
I. C. J. WOOD, S. HODI and L. MORGAN \\ Manchester and Stockport
}

\begin{abstract}
SUMMARY
Using cycloplegia, the change in ametropia of 113 infants was followed at 3 month intervals over the first year of life. Scatterplots of the spherical equivalent power show that the dioptric differences exhibit a significant myopic shift of -0.38 ds between 26 and 36 weeks and -0.38 ds between 36 and 52 weeks. The spread of the dioptric differences $(95 \%$ CI) does not appear to be related to the magnitude of the ametropia present and decreases with time. By 12 months of age the frequency distribution of the spherical equivalent appears to become leptokurtic as it is in the adult. On average the astigmatism was of low degree (less than 1 dioptre cylinder) and with the rule. Anisometropia was rarely seen. The results of this longitudinal study point to an optimal time for screening and perhaps prescribing for 'abnormal' refractive error between 9 and 12 months of age.
\end{abstract}

The purpose of this study was to follow the pattern of development and change in refractive error in a voluntary population. As many of the parents of these infants had histories of ametropia, amblyopia or strabismus it was hoped the results of this study might show the longitudinal refractive norms for spherical and astigmatic ametropia for a local 'atrisk' infant population. Early longitudinal studies ${ }^{1}$ had a small number of participants and used a variety of cycloplegic agents. These studies reveal the mean spherical equivalent refractive error at birth to be +2.00 dioptres in full-term infants, decreasing to 1.0 dioptre at 12 months. This trend to emmetropia is confirmed by larger, more recent longitudinal studies $^{2,3}$ which show a decrease in hypermetropia from a value greater than +2.50 dioptres at 6 weeks and 11 weeks of age, to less than 1.0 dioptres at 12

From: Department of Optometry and Vision Sciences, UMIST, PO Box 88, Manchester, and Department of Ophthalmology, Stepping Hill Hospital, Stockport, UK.

Correspondence to: Dr I. C. J. Wood, Department of Optometry and Vision Sciences, UMIST, PO Box 88, Manchester M60 1QD, UK. months. Premature infants, on the other hand, appear to exhibit lower degrees of hypermetropia, with approximately half being in the myopic range at birth. This 'myopic' trend decreases so that emmetropia is achieved at 12 months. ${ }^{4}$

Longitudinal studies of astigmatism in infancy reveal a more complicated developmental picture, with different test populations showing varying amounts of astigmatism changing both in orientation and with time. The photorefraction studies of Atkinson et $a .^{5}$ revealed that only 3 of 20 infants retained an error of greater than 0.75 dioptre after 18 months. They conclude that early with-the-rule (negative axis 90) astigmatism disappears rapidly in the first 18 months, leading to a preponderance of against-the-rule astigmatism at 2-3 years of age. Gwiazda et al. ${ }^{6}$ suggest that there are equal amounts of with and against the rule astigmatism over 1 dioptre in infancy. Abrahamsson et al. ${ }^{7}$ indicated that there was a greater incidence of against-the-rule astigmatism which decreased between 1 and 2 years of age. However, the recent studies of Thompson ${ }^{8}$ and Edwards ${ }^{2}$ show that with-the-rule astigmatism is the more common in infancy.

We therefore hoped in this study partially to unravel the developmental pattern of both spherical and astigmatic ametropia and to define the extremes of the distributions of refractive error which are known to increase the risk of amblyopia and strabismus. ${ }^{9}$ These data would provide essential normative information for screening programmes.

\section{METHODS}

Full-term infants (38-40 weeks of gestation) were recruited to the project on a voluntary basis from Stepping Hill Maternity Hospital, Stockport. Mothers were asked to bring their babies in five times during the first year: at 2 weeks, 3 months, 6 months, 9 months and 12 months after birth. This resulted in the recruitment of 113 children $(52 \%$ boys and $48 \%$ girls). There was a high incidence of family 
history of squint or amblyopia in the sample (43\%). Fifteen of the children attended for one visit only; therefore some degree of longitudinal data was found on 98 children. Sixty-six (66) infants managed to attend four or five times. The number of satisfactory results varied with age, the lowest being 58 refractions at the first ( 2 week) visit.

On each visit, the babies were tested with preferential looking acuity gratings and received an orthoptic examination including cover, motility tests and ability to overcome a 20 dioptre base out prism. One drop of $0.5 \%$ or $1 \%$ cyclopentolate was administered and depth of cycloplegia assessed by the stability of the retinoscopy reflex after 20 minutes. The $0.5 \%$ cyclopentalate was selected for use on all 2-week-old children and some of the 3month-old children, so that any difference between refractive error found in infants who had received $0.5 \%$ and $1 \%$ could be assessed. When the retino-

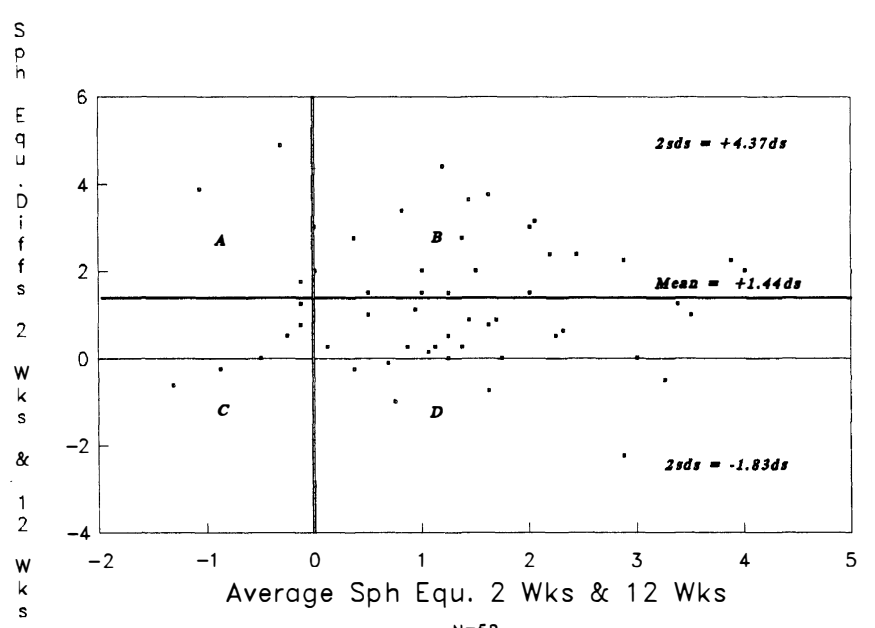

(a)

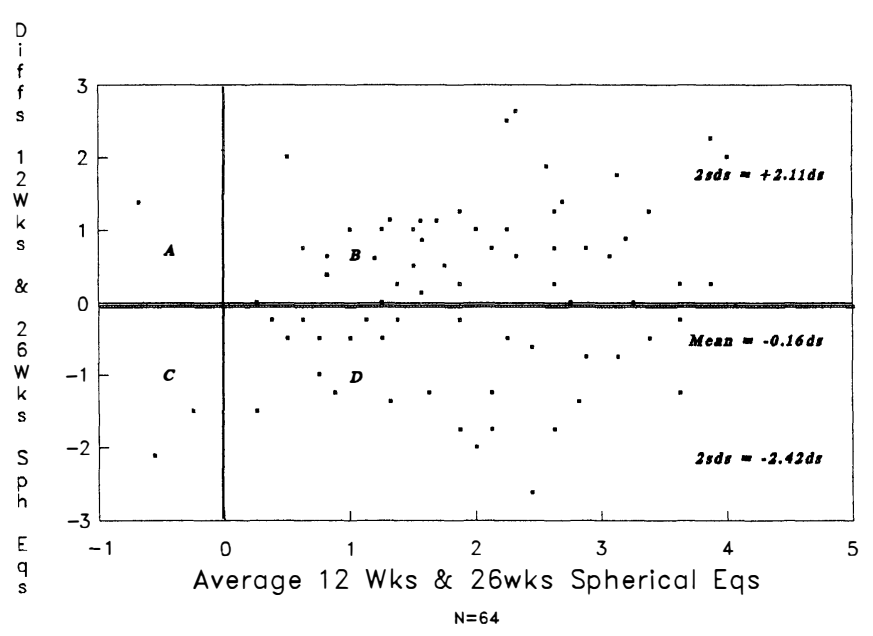

(b) scopy reflex proved to be stable then static spot retinoscopy was carried out. Informed consent was obtained from all parents after each of these procedures had been fully explained.

\section{Statistical Analyses}

Altman and Bland ${ }^{10}$ offered some simple graphical alternative to correlations for quantifying and representing a repeated measurement procedure. By plotting the difference between the repeated measures against the average of the two repeated measures we will be able to show the dioptric change between each visit of the spherical equivalent and cylindrical cycloplegic retinoscopy measurements. In these paired difference analyses, the earlier measurement is always subtracted from the subsequent measurement. Matched pair $t$-test analysis was performed with the repeated measures and the significance level determined using the Bonferroni

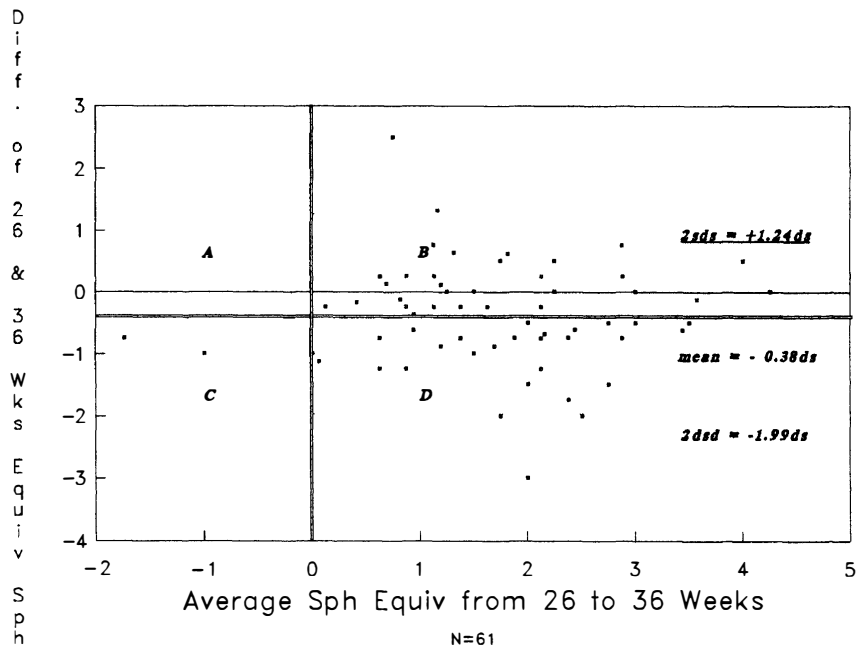

(c)

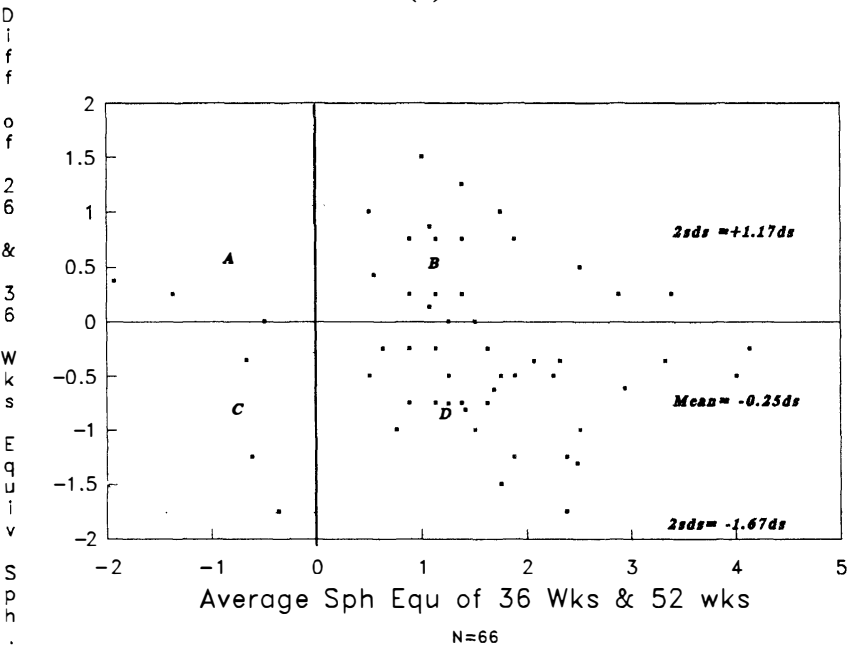

(d)

Fig. 1. The differences of the right spherical equivalent refraction, RSER (spherical + half the cylindrical measurement in dioptres), are plotted against the average RSER value for each pair of visits of the strictly longitudinal group of infants who were seen four or five times over a 12 month period. (a) Change between 2 and 12 weeks ( \pm 2 weeks). (b) Change between 12 and 26 weeks ( \pm 2 weeks). (c) Change between 26 and 36 weeks ( \pm 2 weeks). (d) Change between 36 and 52 weeks ( \pm 2 weeks). 
Table I. Mean differences and associated $95 \%$ confidence intervals of the spherical equivalents for each visit

\begin{tabular}{lllllll}
\hline Interval (weeks) & Mean diff. ds & $t$-diff. ds & $n$ & $2 t$ prob. & $95 \%$ CI & CI range \\
\hline $2-12$ & +1.40 & 6.52 & 59 & 0.0125 & 6.13 & $+4.3 \mathrm{ds} /-1.83$ \\
$12-24$ & -0.16 & 1.23 & 64 & NS & 4.53 & $+2.11 /-2.42$ \\
$24-36$ & -0.38 & 4.00 & 61 & 0.0125 & 3.23 & $-1.24 /-1.99$ \\
$36-52$ & -0.25 & 2.82 & 60 & 0.006 & 2.16 & $+1.17 /-1.67$ \\
\hline
\end{tabular}

approach of decreasing the significance level to a lower probability. In this study the differences in five repeated measurements were obtained. Therefore the significance levels were altered from 0.05 to 0.0125 to take the repeated analysis into account. We report those blind retinoscopy results which were judged consistent for both retinoscopists (S.H. and I.W.). ${ }^{11}$

\section{Control Experiment for Levels of Cycloplegia}

Decreased levels of cycloplegia using $0.5 \%$ cyclopentalate at 1 month did not appear to affect the refractive findings in 10 infants when the same $0.5 \%$ dose was administered to a control group of 3month-old infants (matched pair $t$ difference 0.33 , d.f. $=9, p=0.75)$.

\section{RESULTS}

\section{Change in Spherical Equivalent Refraction}

From 2 Weeks to 12 Weeks ( \pm 2 Weeks): Fig. 1a The 6 infants $(10 \%)$ in area $A$ with low myopic errors (<-1.25 ds) show a low hyperopic shift similar to the 41 infants $(70 \%)$ in B who became significantly more hypermetropic (mean $=+1.44 \mathrm{ds}$ ) by the second (12 weeks) visit as shown in Table I. The remaining 8 infants in $\mathrm{C}$ and $\mathrm{D}$ became slightly $(>-1$ D) myopic.

The relatively uniform spread of the data points of Fig. 1a appears to show that these differences are independent of the size of the refractive error. The range of the $95 \%$ confidence intervals in Table I shows the wide spread in the differences of spherical equivalent $(+4.37$ to $-1.83 \mathrm{ds})$ in this age group.

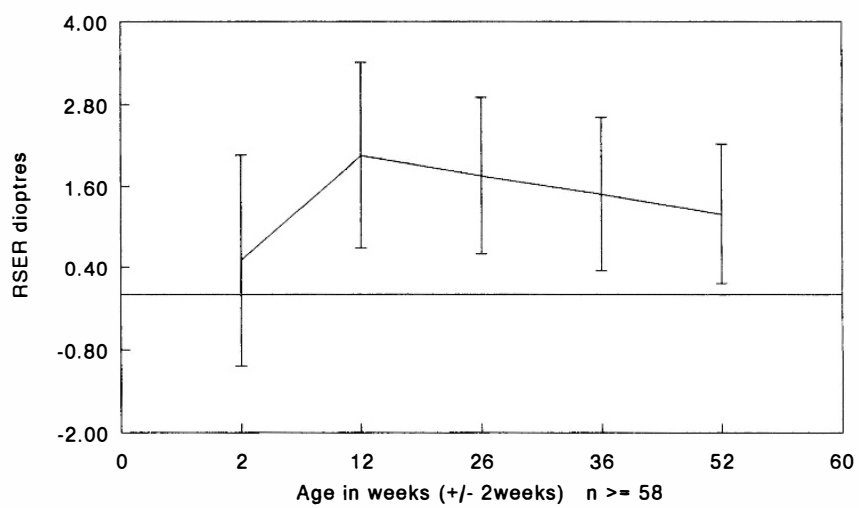

Fig. 2. The mean and standard deviation of RSER plotted against each of the five visits in weeks. Number subjects on each visit is as per Fig. 1.
Between 12 Weeks and 26 Weeks ( \pm 2 Weeks): Fig. $1 \mathrm{~b}$ Of 64 infants participating at this stage of the project, one low myope in A became more hyperopic $(+1.25 \mathrm{ds})$ and the low myopes in $\mathrm{C}$ appear to change in a myopic direction $(<2.00 \mathrm{ds})$. The lower hypermetropic changes in B for those 38 infants $(57 \%)$ with hypermetropic error are counterbalanced by the 28 infants $(42 \%)$ in D who showed slightly fewer but larger myopic changes. Table I shows there is a non-significant myopic shift and a decrease in the spread of the differences of the spherical equivalent ( $95 \%$ confidence intervals +2.11 ds to $-2.42 \mathrm{ds}$ ).

Between 26 Weeks and 36 Weeks ( \pm 2 Weeks): Fig. 1c In this sample of 61 infants, the two myopic infants (3\%) in $\mathrm{A}$ and $\mathrm{C}$ show a small increase of myopia from 26 to 36 weeks. The hypermetropic infants in areas $\mathrm{B}$ and $\mathrm{D}$ show that there are a greater number (37) of infants $(60 \%)$ showing a myopic shift than the 15 infants $(24 \%)$ showing a hypermetropic shift. This is coupled with a decrease in the spread of differences in the spherical equivalent between 26 and 36 weeks $(95 \%$ confidence intervals +1.24 ds to $-1.99 \mathrm{ds})$. Table I confirms that the average small significant myopic shift of -0.38 ds occurs between 26 and 36 weeks for this sample.

Between 36 Weeks and 52 Weeks ( \pm 2 Weeks): Fig. 1d The further significant -0.25 ds myopic shift is shown together with decreased spread in this group of 66 infants. This shift is the net result of a larger decrease

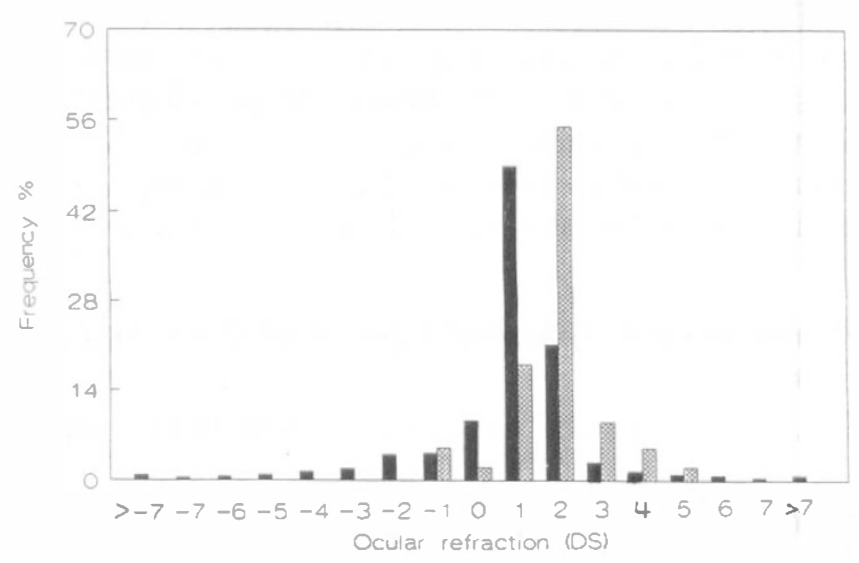

Fig. 3. A frequency plot of spherical equivalent error for the combined studies of Stenstrom, ${ }^{12}$ Stromberg ${ }^{13}$ and Sorsby et al. ${ }^{14}$ (black columns; $n=8187$ ) compared with that of infants aged 12 months in this study (hatched columns, $n=66$ ). 


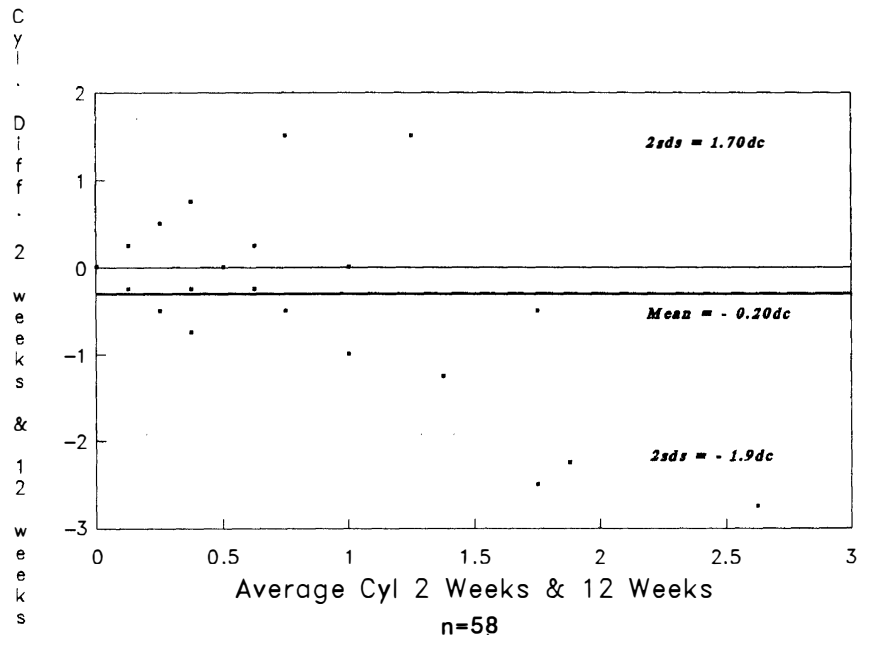

(a)

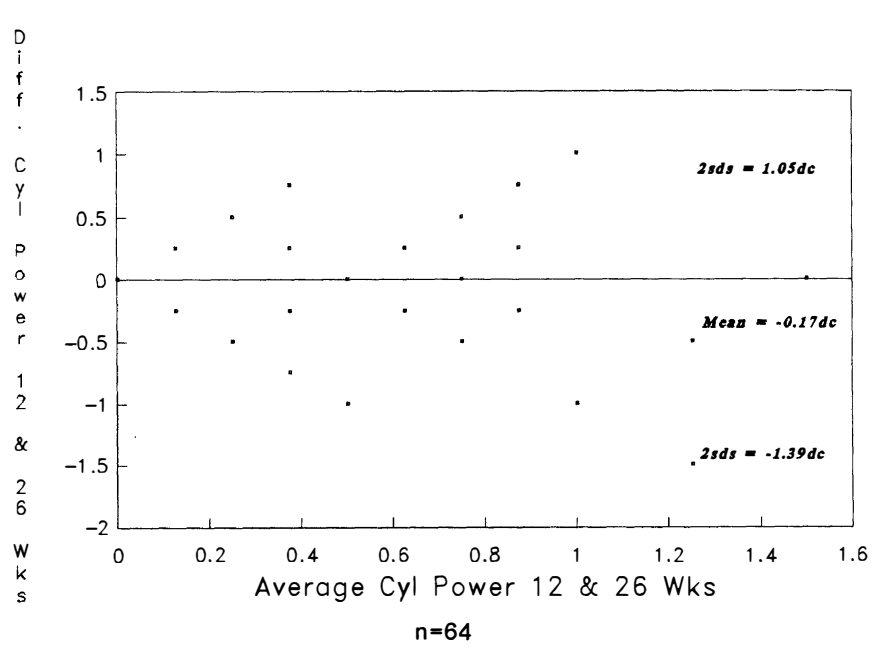

(b)

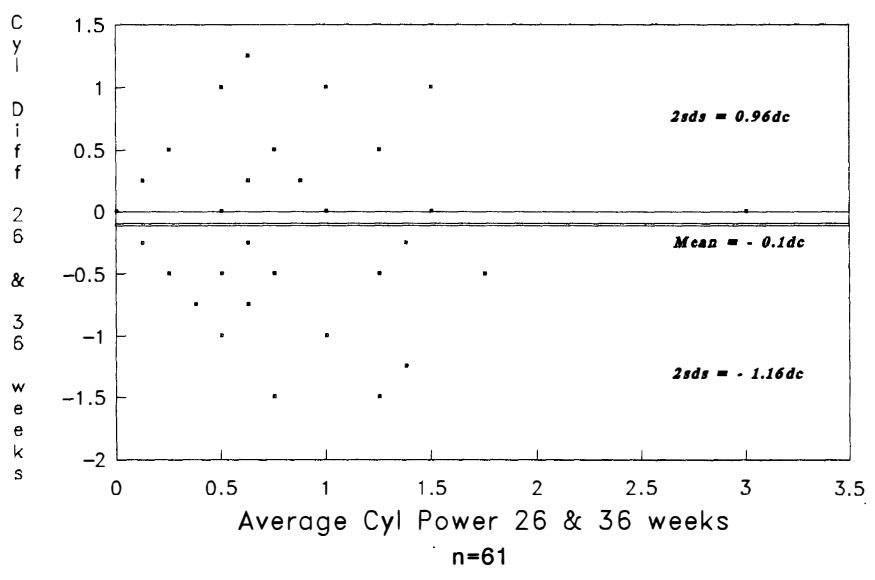

(c)
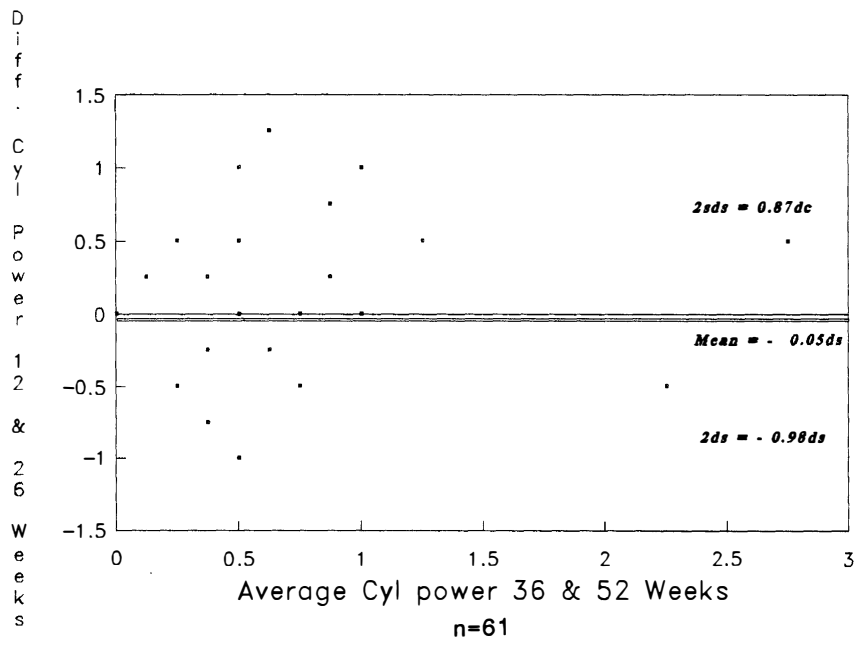

(d)

Fig. 4. The differences of the right cylindrical refraction, Rcyl, in dioptres are plotted against the average Rcyl value for each pair of visits of the strictly longitudinal group of infants who were seen four or five times over a 12 month period. (a) Change between 2 and 12 weeks ( \pm 2 weeks). (b) Change between 12 and 26 weeks ( \pm 2 weeks). (c) Change between 26 and 36 weeks ( \pm 2 weeks). (d) Change between 36 and 52 weeks ( \pm 2 weeks).

in hypermetropia for the 44 infants $(66 \%)$ in D and the smaller increase hypermetropia in those 18 infants $(28 \%)$ in B. Table I shows there is a decrease in the $95 \%$ confidence interval range of spherical equivalent differences for this age group (95\% confidence interval $=+1.17 \mathrm{ds}$ to $-1.67 \mathrm{ds}$ ).

\section{Comparison of Spherical Equivalent Over the First Year}

Fig. 2 confirms the overall reduction in the mean

Table II. Mean refractive error of infants with and without family history at 52 weeks $( \pm 2$ weeks)

\begin{tabular}{lccc}
\hline & No. of cases & Mean & SD \\
\hline With history & 29 & 1.46 & 1.01 \\
No history & 31 & $1.67 \mathrm{ds}$ & 1.19 \\
$t$ value & -0.72 & (d.f. $=58,2$-tailed probability $=0.47$ ) \\
\hline
\end{tabular}

and standard deviation of the spherical equivalent refractive error after the second visit (12 weeks) of this longitudinal study. Fig. 3 shows the spread of refractive errors at 12 months compared with a summary of work on the spread of refractive error in adults by Stenstrom, ${ }^{12}$ Stromberg ${ }^{13}$ and Sorsby $e t$ $a l{ }^{14} \mathrm{By}$ the time of the last visit (52 weeks) the distribution pattern of ametropia is similar to that in adults, taking into account the small hyperopic shift reported by Glickstein and Millodot. ${ }^{15}$

Table III. Matched pair $t$-test for cylindrical power on subsequent visits

\begin{tabular}{lcccc}
\hline Time & $n$ & $t$-diff. & Significance & $p$ value \\
\hline 12 v. 26 weeks & 64 & 1.74 & NS & $<0.0125$ \\
26 v. 36 weeks & 61 & 1.70 & NS & $<0.0125$ \\
36 v. 52 weeks & 61 & 1.00 & NS & $<0.0125$ \\
\hline
\end{tabular}




\section{Change in Spherical Equivalent with Family History}

Table II shows there is no difference in the mean refractive error between those infants with a family history of ametropia, strabismus and amblyopia and those infants without this history.

\section{Change in Cylindrical Power}

From 2 Weeks to 12 Weeks ( \pm 2 Weeks): Fig. $4 a$ Analysis of the 58 infants shows that the change in cylinder powers seems to be proportional to the cylinder power averaged from 2 weeks to 12 weeks. The greatest change and reduction in cylinder power is apparent for cylinder powers greater than $1.5 \mathrm{dc}$. If these large changes are eliminated from the cylinder data set, the mean difference of 1.35 ds spherical

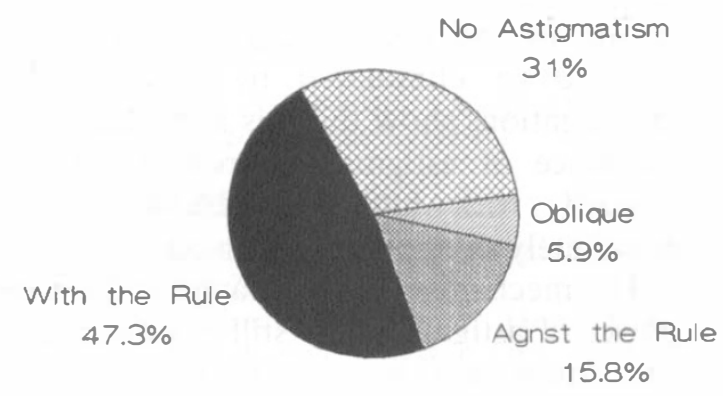

4 weeks $+1-2$ weeks $n=58$

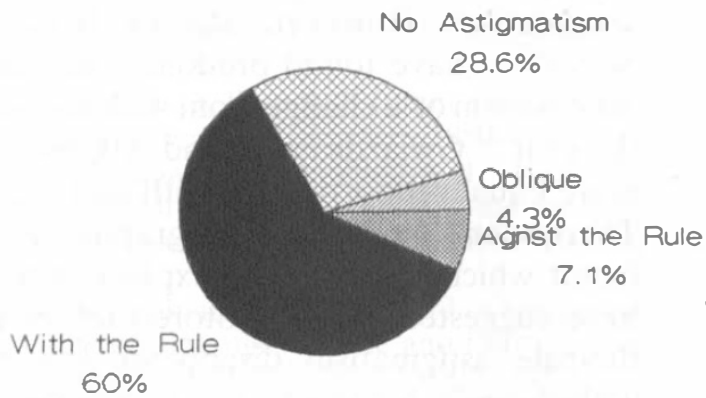

26 weeks $+/-2$ weeks $n=61$ equivalent power between 2 weeks and 12 weeks is still significantly different $(t$ difference $=6.52$, d.f. $=56, p>0.0125)$.

From 13 Weeks to 52 Weeks ( \pm 2 Weeks): Fig. 4b A similar change is noted for cylinder powers above $1.00 \mathrm{dc}$ for the 12-26 week period in Fig. 5b. Fig. 5c and $\mathrm{d}$ show that the gradual decrease in the magnitude of cylinder power continues with increasing age. Table III, however, shows that the change of cylinder power is not statistically significant. Astigmatic errors recorded in the first 6 months were most likely to disappear before age 1 year. Astigmatic errors appearing in the second 6 months were more likely to persist. At 12 months only 3 astigmatic

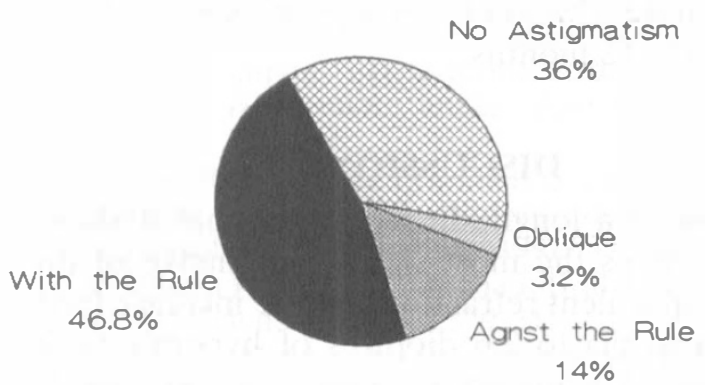

12 weeks $+1-2$ weeks $n=64$

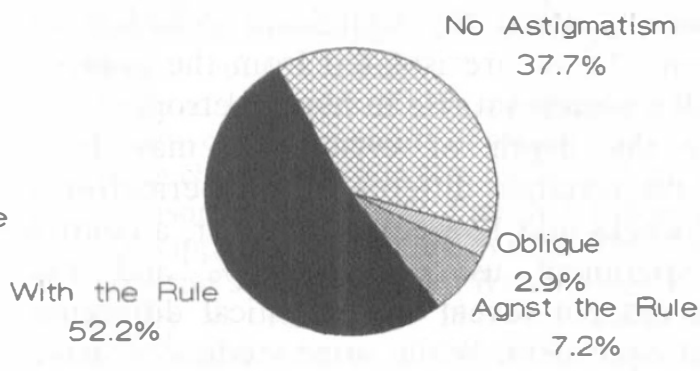

36 weeks $+1-2$ weeks $n=61$

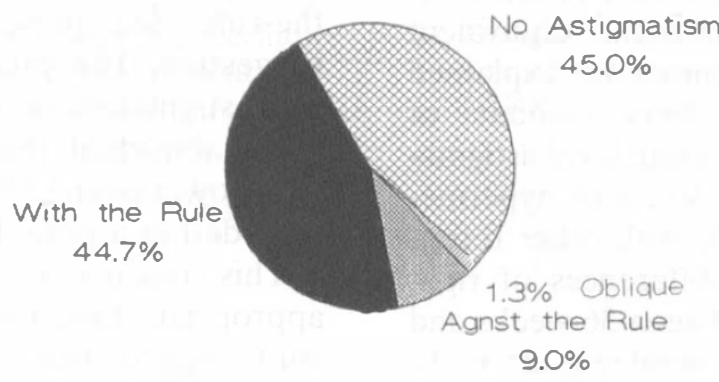

52 weeks $+1-2$ weeks $n=61$

Fig. 5. Pie diagrams of the distribution of cylinder axes in infancy, showing that the majority of astigmatic infants present with with-the-rule astigmatism, i.e. negative cylinder axis set at 90. 
errors over $1.50 \mathrm{dc}$ were present, none of which was present before 6 months.

\section{Axis Direction of the Astigmatic Error}

Fig. 5 shows the astigmatic errors were overwhelmingly with the rule throughout the 12 month period.

\begin{abstract}
Anisometropia
Anisometropia over 1 dioptre was rare and found in only $6(1.3 \%)$ individual examinations. In children less than 6 months the anisometropia subsequently disappeared. Only 2 children of 6 months or over showed anisometropia. The anisometropia was associated in one case with a large persistent hypermetropic error of greater than 4 dioptres which subsequently disappeared. In the other case, the anisometropia did not develop to be greater than 1 dioptre until 12 months of age; it then persisted over the next 12 months.
\end{abstract}

\section{DISCUSSION}

The benefit of a longitudinal study is that it shows change. Perhaps the most significant change of the spherical equivalent refraction was the increase from near emmetropia to 2.6 dioptres of hypermetropia observed in $75 \%$ infants between 2 weeks and 12 weeks ( \pm 2 weeks). This change has not previously been documented. Some of the changes in spherical equivalent refractive error can be explained by changes in the magnitude of the cylinder component. However, when the significant cylinders of greater than $+1.5 \mathrm{dc}$ are isolated from the analysis there is still a significant rise in hypermetropia.

Similarly the depth of cycloplegia may have influenced the resultant difference in hypermetropia between 2 weeks and 12 weeks. However, a control masked experiment using both $0.5 \%$ and $1 \%$ cycloplegia did not reveal any statistical difference in spherical equivalent. While some studies ${ }^{16,17}$ have hinted that this increase in hypermetropia may be a possibility, others ${ }^{1,8}$ are at variance with this finding. Banks $^{1}$ and Thompson ${ }^{8}$ found hypermetropia greater than +2.00 ds to be normal in neonates. The small but significant decrease in the spherical equivalent hypermetropia after 26 weeks cannot be explained by either the influence of the large amounts of hyperopia decreasing or the decreasing level astigmatism. The gradual decline to low levels of hypermetropia by 12 months is compatible with other recent studies. $^{2,8}$ The decrease in the differences of right spherical equivalent refraction between 36 weeks and 52 weeks, as denoted by the $95 \%$ confidence intervals, perhaps indicates the stabilisation/emmetropisation of the refractive error.

Surprisingly there is no statistical difference between those infants with a family history of refractive error strabismus and amblyopia and those without a family history. However, it is likely that only $25 \%$ of those infants with refractive errors greater than $+3.50 \mathrm{ds}$ are at risk. ${ }^{8,18}$ Taking into account the small eye effect, ${ }^{15}$ there is no significant difference between the adult and infant distributions of spherical equivalent error.

In this study the greatest incidence and spread of astigmatic power values were found in the youngest infants. Both the incidence and spread of astigmatic error decrease by 3 months, although we did have some cases of increasing astigmatism from the 3-6 month level. This finding complements Thompson's ${ }^{8}$ observations. However, Mohindra et al., ${ }^{19}$ using near retinoscopy, reported low degrees of astigmatism in the youngest infants followed by an increase in incidence between 2 and 7 months. Gwiazda et al. ${ }^{6}$ found that the highest incidence of astigmatism occurs in the first 2 years of life and is greatly reduced or eliminated by 4 years of age. All investigations show there is a gradual decline in the incidence of astigmatism from 12 months of age onward, with higher astigmatic magnitude not completely disappearing with age.

The mechanism of the change in the incidence and power of astigmatism is still not clear. Explanations vary from tensions on the horizontal extraocular muscles ${ }^{20}$ the eyelids on the corneal profile ${ }^{21}$ or the presence of a large angle lambda. ${ }^{22}$ In common with these recent studies ${ }^{2,8}$ our study also shows that a high proportion of the infants display with-the-rule astigmatism. However, studies from the United States ${ }^{19-21}$ have found predominant against-the-rule astigmatism or a change from with to against through the year. ${ }^{23}$ Gwiazda et al. ${ }^{6}$ and Atkinson et al. ${ }^{5}$ found more equal proportions of with and against the rule. There seems to be some geographic variation in this factor which is difficult to explain. Atkinson et al. ${ }^{24}$ have suggested, using photorefraction, that againstthe-rule astigmatism disappears less readily than with-the-rule, leading to a preponderance of againstthe-rule at a later stage. Since the incidence of against-the-rule is so low in this study, and all cases of significant astigmatism at 12 months were withthe-rule, the present study cannot support this suggestion. The present authors feel that with-therule astigmatism in infants should not be regarded as 'more abnormal' than against-the-rule. Any astigmatism power over 1.50 dioptres at 12 months should be regarded as a potential amblyogenic risk factor. ${ }^{9}$

This conclusion raises the question as to the most appropriate time for screening this age group. Our study suggests that refractive screening should not be undertaken at or before 6 months as large changes of refractive error are still occurring at this point. For instance, of 9 children in the study with hypermetropia greater than 4 dioptres at 6 months, 5 showed a 'normal' (within 1 standard deviation of the mean) 
level of hypermetropia by 12 months. If spectacles had been prescribed for the high hypermetropic group at 6 months the incidence of squint in compliant patients might have decreased, ${ }^{25}$ or it might not. ${ }^{26}$ However, the results seen here suggest that 5 of $9(62 \%)$ of those children would have worn spectacles needlessly. The wearing of these spectacles might also have impeded the emmetropisation process. ${ }^{18,27}$ Refractive error at 6 months was a poor predictor of children who became myopic by 12 months, as most were still hypermetropic at this stage. Furthermore, the two persistent anisometropes seen in this study were not detected until 12 months or later. The evidence of this study suggests that 12 months or later might be a better age to choose if refractive screening is to be undertaken.

The authors thank the staff of Stepping Hill Hospital, Stockport, for their help and support.

Key words: Anisometropia, Astigmatism, Cycloplegic retinoscopy, Infant refraction, Longitudinal development

\section{REFERENCES}

1. Banks M. Infant refraction and accommodation. Int Ophthalmol Clin 1980;20:205-32.

2. Edwards M. The refractive status of Hong Kong Chinese infants. Ophthalmic Physiol Opt 1990;11: 297-303.

3. Hopkinson B, Arnold P, Billingham M, McGarricle M, Shribman S. Can retinoscopy be used to screen infants for amblyopia? A longitudinal study of refraction in the first year of life. Eye 1992;6:607-9.

4. Scharf J, Zonis S, Zelter M. Refraction in premature babies: a prospective study. J Pediatr Ophthalmol Strabismus 1980;15:48-50.

5. Atkinson J, Braddick O, French J. Infant astigmatism: its disappearance with age. Vision Res 1980;40:891-3.

6. Gwiazda J, Scheiman M, Mohindra I, Held R. Astigmatism in children: changes in axis and amount from birth to six years. Invest Ophthalmol Vis Sci 1984;25:88-92.

7. Abrahamsson M, Fabian G, Sjostrand J. Changes in astigmatism between the ages of one and four years: a longitudinal study. Br J Ophthalmol 1988;72:145-9.

8. Thompson C. Objective and psychophysical studies of infant visual development. PhD thesis, University of Aston, 1987.

9. Sjorstrand J, Abramsson M. Screening for amblyopia. How useful is it to identify risk indicators? In: Bastantis C, Campos E, Angi M, editors. Crescita dell'Occhio e sviluppo della visione nel bambino. Atti Del Simposio Internazione: 1991,123-33.
10. Altman DG, Bland JM. Measurement in medicine: the analysis of method comparison studies. Statistician 1983;32:307-17.

11. Hodi S, Wood ICJ. Comparison of the techniques of videorefraction and static retinoscopy in the measurement of refractive error in infants. Ophthalmol Physiol Opt 1994;14:20-4.

12. Stenstrom $S$. Untersuchungen über die Variation und Kovariation der optischen Elemente des menschlichen Auges. Acta Ophthalmol (Copenh) 1946;Suppl 26. 1946. (English translation by Woolf D. Am J Optom 1948;25:218-32.)

13. Stromberg E. Ueber Refraktion und Achsenlange des menschlichen Auges. Acta Ophthalmol (Copenh) 1936;14:281-93.

14. Sorsby A, Sheridan M, Leary GA. Vision, visual acuity, and ocular refraction of young men. BMJ 1960;1:1394.

15. Glickstein M, Millodot M. Retinoscopy and eye size. Science 1970;168:605-6.

16. Santonastaso A. La rifrazione oculare nei primi anni di vita. Ann Ottal Clin Ocul 1930;58:852-85.

17. Grignolo A, Rivara A. Observations biometriques sur l'oeil des enfants née à terme et des prematures au cours de la première année. Ann Oculist 1968;201: 817-21.

18. Ingram RM, Arnold PE, Dally S, Lucas J. Emmetropisation, squint, and reduced visual acuity after treatment. Br J Ophthalmol 1991;75:414-6.

19. Mohindra I, Held R, Gwiazda J, Brill S. Astigmatism in infants. Science 1978;202:329-31.

20. Fulton A, Dobson V, Salem D, Mar G, Petersen R, Hansen R. Cycloplegic refractions in infants and young children. Am J Ophthalmol 1980;90:239-47.

21. Dobson V, Fulton AB, Sebris SL. Cycloplegic refraction of infants and young children: the axis of astigmatism. Invest Ophthalmol Vis Sci 1984;25:83-7.

22. London $\mathrm{R}$, Wick $\mathrm{B}$. Changes in angle lambda during growth: theory and clinical application. Am J Optom Physiol Opt 1982;59:568-72.

23. Howland H, Sayles N. Photokeratometric and photorefractive measurements of astigmatism in infants and young children. Vision Res 1985;25:73-81.

24. Atkinson J, Braddick O, French J. Infant astigmatism: its disappearance with age. Vision Res 1980;40:891-3.

25. Atkinson J, Braddick O, Wattam-Bell J, Durden K, Bobier W, Pointer J. Photorefractive screening of infants and effects of refractive correction. Invest Ophthalmol Vis Sci 1987;(Suppl)28:399.

26. Ingram RM, Arnold P, Dally S, Lucas J. Results of a randomised trial of treating abnormal hypermetropia from the age of 6 months. $\mathrm{Br} \mathrm{J}$ Ophthalmol 1990;74:158-9.

27. Dobson V, Sebris SL, Carlson MR. Do glasses prevent emmetropisation? Invest Ophthalmol Vis Sci 1986;27 (ARVO Suppl):2. 